\title{
Xây dựng hệ thống mô phỏng kiểm soát không lưu tại sân phục vụ trong đào tạo huấn luyện
}

\author{
Lưu Văn Thuần ${ }^{1, *}$, Hồ Thị Vũ Hiền², Phạm Minh Vương
}

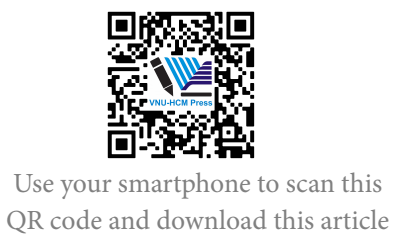

${ }^{1}$ Khoa Kỹ thuật Hàng không, Học viện Hàng không Việt Nam, 104 Nguyễn Văn Trỗi, Quận Phú Nhuận, TP.HCM, Việt Nam

${ }^{2}$ Khoa Không lưu, Học viện Hàng Không Việt Nam, 104 Nguyễn Văn Trỗi, Quận Phú Nhuân, TP.HCM, Việt Nam

Liên hệ

Lưu Văn Thuần, Khoa Kỹ thuật Hàng không, Học viện Hàng không Việt Nam, 104 Nguyễn Văn Trỗi, Quận Phú Nhuận, TP.HCM, Việt Nam

Email: thuanlv@vaa.edu.vn

Lịch sử

- Ngày nhận: 16-08-2019

- Ngày chấp nhận: 25-3-2021

- Ngày đăng: 30-4-2021

DOI : 10.32508/stdjet.v3iSI2.557

\section{Check for updates}

\section{Bản quyền}

๑ Đ ĐHQG Tp.HCM. Đây là bài báo công bố mở được phát hành theo các điều khoản của the Creative Commons Attribution 4.0 International license.

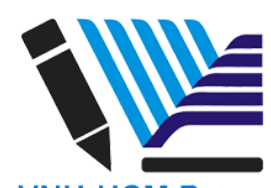

VNU-HCM Press

\begin{abstract}
TÓM TÁ́T
Đây là bài viết nghiên cứu và phát triển hệ thống mô phỏng quá trình điều hành bay diễn ra tại sân bay trong khuôn khổ để tài nghiên cứu khoa học cấp Bộ. Hệ thống mô phỏng điểu khiển không lưu đã trở nên quen thuộc với các nước phát triển. Hơn nữa hiện tại ở Việt Nam, nhu cầu về hệ thống kiểm soát không lưu ngày càng lớn do sự bùng nổ của ngành hàng không dân dụng nói chung và của các nhà cung cấp dịch vụ dẫn đường nói riêng. Tuy nhiên chưa có một nghiên cứu hay một đơn vị nào tại Việt Nam xây dựng hệ thống này. Các Công ty quản lý bay miền Bắc và quản lý bay miền Nam đều mua các hệ thống mô phỏng kiểm soát tại sân với chi phí rất cao từ các công ty, tập đoàn nghiên cứu về hàng không của nước ngoài. Nhiểu công ty khác cũng có nhu cầu về hệ thống này, kể cả các đơn vị quân đội. Nhu cầu này đã thúc đẩy nhóm nghiên cứu tìm kiếm giải pháp để xây dựng hệ thống mô phỏng kiểm soát không lưu phù hợp với nhu cầu đào tạo trong nước. Dựa trên các phần mềm mô phỏng mã nguồn mở riêng lẻ với một số tính năng cơ bản, nhóm nghiên cứu đã xây dựng thành công hệ thống mô phỏng kiểm soát không lưu tại sân kết hợp tái tạo khung cảnh 3D trực quan sinh động ứng dụng trong đào tạo huấn luyện kiểm soát viên không lưu. Hiện hệ thống này đang được áp dụng đào tạo quản lý hoạt động bay tại Học viện hàng không Việt Nam.
\end{abstract}

Từ khoá: Đồ họa 3D, kiểm soát không lưu, kiểm soát tại sân, mã nguồn mở, phần mềm mô phỏng

\section{GIỚI THIỆU}

Đối với mỗi quốc gia, ngành hàng không luôn đóng một vai trò quan trọng, không chỉ là một phương thức vận chuyển hàng khách, hàng hóa đơn thuần, mà còn là cầu nối với các nước xung quanh, quảng bá hình ảnh đất nước con người. Trong những năm gần đây, cùng với sự phát triển mạnh mẽ của công nghệ, khoa học kỹ thuật, nhu cầu sử dụng các dịch vụ hàng không tăng lên đáng kể trong mọi lĩnh vực: vận chuyển hành khách, hàng hóa, hành lý... làm gia tăng áp lực đối với những nhà cung cấp dịch vụ hàng không. Để đáp ứng được nhu câuu đó ngoài việc phải nâng cao trang thiết bị máy móc, cải tiến quy trình, cập nhật kiến thức mới, thì một trong những vấn đề quan trọng không thể bỏ qua đó là đào tạo được đội ngũ nguôn nhân lực có chuyên môn, có trách nhiệm và chịu được áp lực công việc.

Hàng không là một ngành đặc thù, với tính chất nghề nghiệp đặc biệt, trách nhiệm lớn, chỉ một sai sót nhỏ cũng có thể ảnh hưởng đến toàn bộ hành khách và phi hành đoàn trên chuyến bay. Thế nên yếu tố an toàn luôn được đặc biệt xem trọng trong quá trình đào tạo. Tuy nhiên, để đảm bảo các tiêu chí an toàn cho chuyến bay thì các nhân viên hàng không phải được tiếp xúc với thực tế, làm quen với trang thiết bị máy móc, tập xử lý tình huống trong phòng mô phỏng (simulator SIM) trong quá trình đào tạo. Nhưng không phải cơ sở đào tạo nào cũng đủ kinh phí để lắp đặt hệ thống SIM mô phỏng thực tế, phân vì chi phí lớn, phân vì không đủ nhân lực có trình độ cao để sửa chửa, bảo trì, nâng cấp hệ thống sao cho phù hợp với thực tế thay đổi từng ngày của ngành hàng không. Ngoài những hệ thống SIM liên quan đến đào tạo phi công - người chịu trách nhiệm chính cho an toàn của chuyến bay, thì một trong những SIM không kém phần quan trọng và có chi phí đầu tư lớn đó là SIM mô phỏng điều hành không lưu dành cho kiểm soát viên không lưu.

Trên thực tế, tại Việt Nam việc đào tạo kiểm soát viên không lưu còn rất hạn chế. Vì là ngành nghề đặc thù nên hiện nay chỉ có hai đơn vị trực tiếp đào tạo, đó là Học viện Hàng không Việt Nam và Trung tâm đào tạo huấn luyện của Tổng công ty quản lý bay Việt Nam. Đối với doanh nghiệp là Tổng công ty quản lý bay Việt Nam vì nhu câu sử dụng nguôn nhân lực tại chỗ, phải huấn luyện thường xuyên (huấn luyện năng định, huấn luyện định kỳ, huấn luyện nâng cao) nên các đơn vị này đầu tư nhập toàn bộ trang thiết bị (phần cứng và phần mềm) của nước ngoài, ví dụ minh họa Hình 1. Tuy nhiên giá thành của các hệ thống này thường rất cao, và chỉ các đơn vị lớn như công ty quản lý bay miền Bắc và miền Nam được trang bị hệ thống này. 


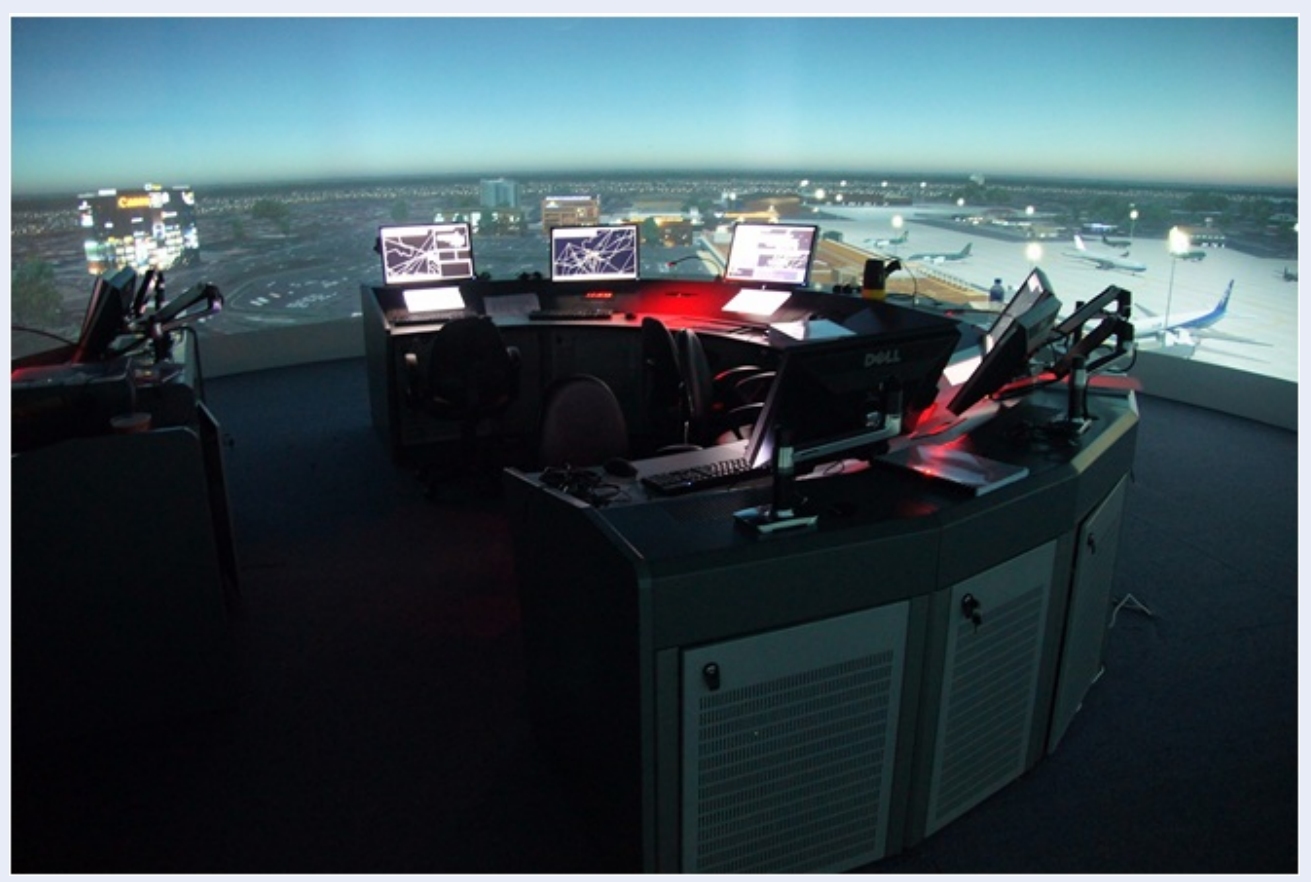

Hình 1: Phòng SIM kiểm soát tại sân - công ty Quản lý bay miền Nam

Việc đào tạo kiểm soát viên không lưu tại Học viện Hàng không Việt Nam còn rất hạn chế. Hệ thống thiết bị hiện có là hệ thống ScanSim đâu tư năm 2000 trong khuôn khổ dự án ODA, với tổng kinh phí đâu tư gần 2 triệu USD. Tuy nhiên hiện nay công nghệ này đã hoàn toàn lạc hậu và không sử dụng được nữa do các hỏng hóc về phẩn cứng và phần mềm. Năm 2010, tác giả Lưu Trung ${ }^{1}$ đã thực hiện đề tài nghiên cứu khoa học cấp Bộ nhằm khắc phục những hỏng hóc này. Tuy nhiên hiệu quả mang lại không lớn và hệ thống không thể phục vụ nhu câu đào tạo của Học Viện. Nếu làm mới lại hệ thống ScanSim thì dự trù kinh phí cũng gần bằng số tiền đầu tư ban đâu (gần 2 triệu USD). Do đó, việc nghiên cứu xây dựng phát triển hệ thống mô phỏng mới phù hợp với nhu câu đào tạo cũng như nguôn kinh phí hạn hẹp là nhu cầu cấp bách.

\section{PHƯƠNG PHÁP NGHIÊN CỨU}

Nhóm nghiên cứu tiến hành nghiên cứu, giải mã công nghệ, xây dựng mô hình hệ thống kiểm soát không lưu tại sân bay theo công nghệ $3 \mathrm{D}$ dùng cho đào tạo kiểm soát viên không lưu tại Học viện Hàng không Việt Nam. Mô hình giải pháp được xây dựng dựa trên sân bay Tân Sơn Nhất, thực hiện nhằm mục đích cung cấp giải pháp đào tạo thực hành kiểm soát tại sân cho học sinh - sinh viên, tạo cơ hội tiếp cận với mô hình điều khiển không lưu và mô hình mô phỏng bay thực tế tại sân bay Tân Sơn Nhất, nâng cao năng lực đào tạo kiểm soát viên không lưu cho Học viện Hàng không Việt Nam nói riêng và cho Việt Nam nói chung, cải thiện kỹ năng kiểm soát tàu bay cho học viên từ đó mở ra nhiêu cơ hội việc làm sau khi tốt nghiệp cho học viên.

Một hệ thống kiểm soát không lưu (ATC) tại sân cơ bản được minh họa trên Hình 2 bao gồm các thành phân cơ bản: mô đun mô phỏng quản lý không lưu, mô đun mô phỏng đồ họa, phần mềm quản lý chung. Toàn bộ hệ thống được kết nối thông qua mang nội bộ LAN. Mô đun mô phỏng quản lý không lưu sẽ thực hiện vai trò mô phỏng các tình huống quản lý không lưu giả định như cất hạ cánh, lai dắt hay lăn trên sân đỗ... Mô đun mô phỏng đồ họa sẽ thể hiện các khung cảnh sân bay, tàu bay và sự vận hành của các đối tượng để minh họa các tính huống giả định. Mô đun này thường bao gồm một hệ thống gồm nhiều máy tính cấu hình cao và máy chiếu độ phân giải cao để đảm bảo sự hiển thị và hoạt động trơn tru của các đối tượng và tình huống. Phần mềm quản lý chung có vai trò kết nối thông tin giữa hai mô đun để đảm bảo đông bộ về mặt cơ sở dữ liệu và thông tin liên kết. Dựa trên cấu hình chung này, nhóm tác giả sẽ xây dựng hệ thống ATC phục vụ đào tạo huấn luyện.

Quá trình nghiên cứu xây dựng hệ thống mô phỏng kiểm soát không lưu tại sân sẽ được thực hiện lần lượt qua các bước: xây dựng phần mềm mô phỏng kiểm soát không lưu, xây dựng phân mềm mô phỏng bay, 


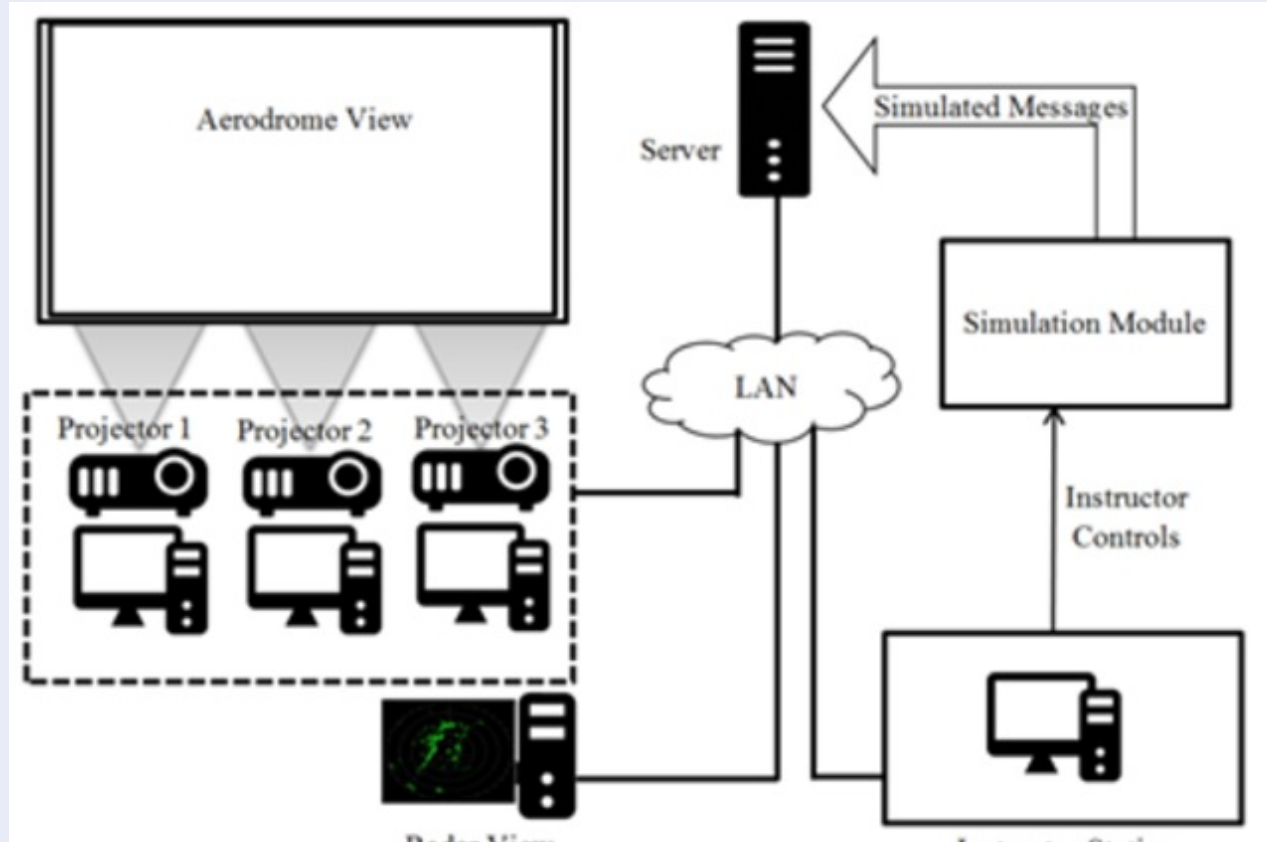

Radar View

Hình 2: Cấu hình cơ bản của hệ thống mô phỏng ATC²

kết nối hệ thống và xây dựng trang thiết bị phần cứng, lắp đặt và thử nghiệm. Các bước tiến hành sẽ được trình bày lân lượt trong các phân tiếp theo của bài báo.

\section{XÂY DỰNG MÔ ĐUN MÔ PHỎNG THÁP ĐIÊUU KHIỂN KHÔNG LƯU}

Kiểm soát tại tháp điều khiển bao gồm các hoạt động và quy trình để kiểm soát chuyển động của bất kỳ phương tiện nào (vật thể trên mặt đất và vật thể bay) trong ranh giới sân bay. Ranh giới này thường được định nghĩa là một khối lượng không phận với bán kính 2-30 dặm và chiêu cao 1.500 đến 2.000 bộ tập trung tại sân bay. Tháp điều khiển là nơi cao nhất trong sân bay và thường có cửa sổ bao phủ toàn cảnh $360^{\circ}$ xung quanh tháp. Các tác vụ được thực hiện bởi điều khiển ATC có thể được phân loại lại dựa trên các đặc điểm của chúng như được minh họa trong Hình 3. Các tác vụ này được chia thành 3 loại: đường dài, tiếp cận $(\mathrm{APP})$ và tại sân.

Trong khuôn khổ bài báo, nhóm tác giả sẽ tập trung xây dựng phát triển mô đun ATC phục vụ điểu khiển không lưu tại sân. Quá trình phân tích thiết kế mô đun điều khiển tại sân sẽ dựa trên các yêu câu và quy tắc chung của kiểm soát không lưu. Do đó việc tìm hiểu đúng các yêu cầu và quy tắc này sẽ đảm bảo mô đun được phát triển đúng hướng và đây đủ các tính năng.

Các tác vụ chính của điều khiển không lưu tại sân bao gồm: liên lạc với tàu bay, chỉ dẫn lăn, cất cánh, hạ cánh và chuyển giao tàu bay cho cơ quan kiểm soát tiếp cận. Mỗi tác vụ đòi hỏi kiểm soát viên phải nắm được các thông tin, quy tắc chung cho từng loại tàu bay cũng như đặc điểm của sân bay. Do đó, trong quá trình huấn luyện, học viên quản lý không lưu phải được đào tạo và thực hành đây đủ các tiêu chí đối với tù̀ng tác vụ.

Đối với tàu bay khởi hành, học viên sẽ thực hành theo các nội dung sau:

- Thiết lập liên lạc với tàu bay;

- Cấp chỉ thị cho tàu bay lăn;

- Phân cách các tàu bay khởi hành;

- Phân cách tàu bay với các phương tiện khác;

- Cấp huấn lệnh cho tàu bay cất cánh;

- Theo dõi diễn tiến của tàu bay \& ghi băng phi diễn;

- Thông báo tin tức không lưu;

- Chuyển giao kiểm soát tàu bay cho APP.

- Sử dụng thuật ngũ phù hợp.

Trong bài thực hành này, học viên cân lưu ý các quy định về đường cất hạ cánh áp dụng cho từng loại tàu bay để ra đúng chỉ dẫn. Trong quá trình tàu bay di chuyển ra đường băng, các quy định về đường lăn dành cho từng loại tàu bay cũng phải được chú ý và thực hiện theo đúng quy định. 


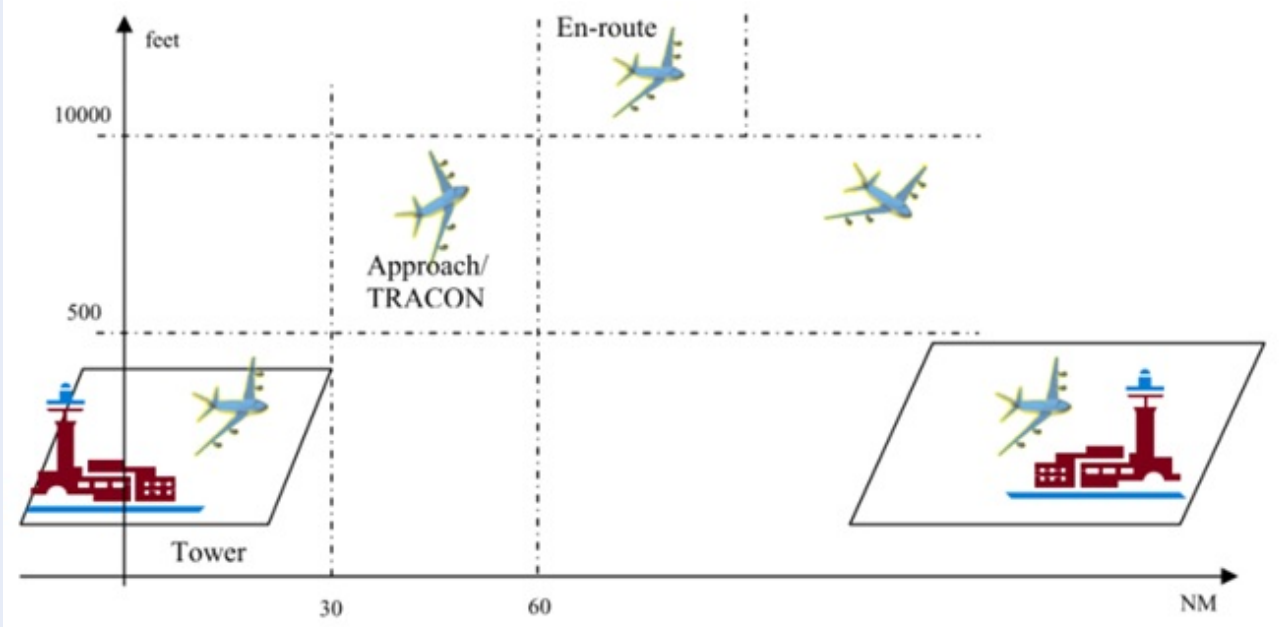

Hình 3: Các trường hợp khác nhau của $\mathrm{ATC}^{3}$

Đối với tàu bay hạ cánh, học viên sẽ thực hành theo các nội dung sau:

- Nhận chuyển giao kiểm soát từ APP;

- Thiết lập liên lạc với tàu bay;

- Thông báo điều kiện hạ cánh, đường cất hạ cánh (CHC);

- Thông báo tin tức liên quan;

- Phân cách giữa các tàu bay đến;

- Cấp huấn lệnh cho tàu bay hạ cánh;

- Cấp huấn lệnh cho tàu bay rời đường $\mathrm{CHC}$, về sân đỗ;

- Theo dõi diễn tiến của tàu bay \& ghi băng phi diễn; Trong bài thực hành này, học viên cần lưu ý các quy định về đường cất hạ cánh, cũng như quy định về tải trọng của từng vị trí đỗ để đưa ra chỉ lệnh phù hợp. Dựa trên các tiêu chí huấn luyện điều khiển không lưu, nhóm tác giả sẽ phân tích và xây dựng mô đun điều khiển không lưu tại sân. Xu hướng phát triển chung của các phần mềm ATC phi thương mại là phát triển và cải tiến dựa trên các phần mềm mã nguồn mở. Nhằm tận dụng những thành tựu mà cộng đồng mã nguôn mở đã đạt được, nhóm nghiên cứu tìm hiểu và nhận thấy có một số phần mềm như OpenScope ${ }^{4}$, OpenRadar ${ }^{5}$, ATC-pie ${ }^{6}$. Cả ba phần mềm mã nguồn mở này đều thực hiện tốt các mô phỏng cất hạ cánh và quá trình tiếp cận của tàu bay. Tuy nhiên phần mềm OpenScope không hỗ trợ mô phỏng kiểm soát mặt đất cũng như việc mở rộng cơ sở dữ liệu cho sân bay bị hạn chế. Do đó phần mềm này không đáp ứng được các tiêu chí cơ bản mà nhóm nghiên cứu đang tìm kiếm. Hai phân mềm OpenRadar và ATC-pie cung cấp nhiều tính năng hơn và đáp ứng gần như đây đủ các tác vụ mong muốn như cất hạ cánh, di chuyển trên sân đỗ. Ngoài ra một tính năng quan trọng được nhóm tác giả chú ý là khả năng mở rộng kết nối với các phần mềm mô phỏng bay. Cả hai phần mềm này đều có thể kết nối với phân mềm FlightGear ${ }^{7}$ - phần mềm mô phỏng bay mã nguồn mở. Tuy nhiên cách kết nối và hiển thị khung cảnh của hai phân mềm có sự khác biệt rõ rệt. OpenRadar chỉ kết nối với FlightGear để thể hiện khung cảnh 3D ngoài cửa sổ tàu bay trong khi ATC-pie cho phép quan sát khung cảnh 3D từ nhiều góc nhìn khác nhau và quan trọng nhất là khung cảnh $3 \mathrm{D}$ nhìn từ đài chỉ huy. Một tính năng quan trọng nổi bật khác của ATC-pie đó là phiên làm việc dạng giáo viên - học viên. Phiên làm việc này đáp ứng nhu câu dạy và thực hành trong quá trình đào tạo huấn luyện. Với những tính năng quan trọng đó, nhóm tác giả lựa chọn phân mềm ATC-pie để tiếp tục khai thác và phát triển.

Phần mềm ATC-pie được phát triển dựa trên ngôn ngữ lập trình Python ${ }^{8}$ cho phần lõi mô phỏng kết hợp với trình đồ họa $\mathrm{Qt}^{9}$ cho phần giao diện người dùng. Ngôn ngữ lập trình Python là một trong nhũng ngôn ngữ lập trình hiện đại phổ biến nhất hiện nay với khả năng mở rộng và kết hợp với nhiêuu ngôn ngũ lập trình từ tính toán số, lập trình web tới những lĩnh vực mới như trí tuệ nhân tạo hay máy học. Phiên làm việc tổng thể của ATC-pie được mô tả trong Hình 4. Phiên làm việc được quản lý chung bởi tác vụ "Session Manager”. Tác vụ này quản lý 4 kiểu phiên làm việc chính gồm: solo, FlightgearMP, teacher session và student session. Trong khuôn khổ của bài báo, nhóm nghiên cứu tập trung vào phiên làm việc giáo viên - học viên. Chức 
năng chính của hai phiên làm việc này được mô tả trong Bảng 1. Các chức năng này được cụ thể hóa trong chương trình và thể hiện qua các thuộc tính và tác vụ, như mô tả trong Hình 5.

Trong quá trình phát triển phần mềm, nhóm nghiên cứu tham khảo ý kiến đóng góp cũng như thăm quan phòng SIM của công ty quản lý bay miên Nam và nhận thấy một tính năng quan trọng của phân mềm đào tạo huấn luyện đó là danh sách tình huống được chuẩn bị sẵn. Với tính năng này, giáo viên có thể soạn sẵn nhiều tình huống mô phỏng khác nhau, lưu lại và sử dụng chung cho các buổi thực hành khác nhau. Do đó, nhóm nghiên cứu và phát triển thêm tính năng này cho phần mêm hiện có.

Tính năng bài thực hành chuẩn bị trước được phát triển dựa trên danh mục mẫu các bài thực hành đang được đào tạo tại khoa Không lưu của Học viện Hàng không. Sau khi xem xét các yếu tố và chuẩn hóa dữ liệu, nhóm tác giả xây dựng được bảng dữ liệu các tính huống mô phỏng được minh họa trong Bảng 2.

Trong phiên bản hiện có, kết nối 1-1 trong phiên giáo viên - học viên hoàn toàn không đáp ứng được nhu câu thực hành theo nhóm của các lớp quản lý không lưu. Do đó, nhóm nghiên cứu tiếp tục cải tiến tính năng và mở rộng khả năng kết nối cho mô đun mô phỏng không lưu. Sau khi mở rộng kết nối, nhiều sinh viên có thể kết nối vào cùng một phiên thực hành của giáo viên và thực hiện luân phiên các chỉ lệnh điều khiển không lưu theo sự hướng dẫn trực tiếp của giáo viên. Sơ đồ kết nối sử dụng mạng LAN cho phiên giáo viên - học viên được minh họa trên Hình 6.

Trong phiên thực hành teacher-student nguyên gốc, sinh viên chỉ có thể quan sát giáo viên thực hiên việc ra chỉ lệnh và điều khiển các tàu bay mà không thể tham gia vào quá trình điều khiển không lưu. Để tăng các hoạt động tương tác của sinh viên ngay trong phiên thực hành, tác giả tiếp tục phát triển thêm tính năng mới, cho phép sinh viên tham gia vào quá trình điêu khiển không lưu. Các tác vụ sinh viên có thể thực hiện để điêu khiển tàu bay được mô tả trên Hình 7 .

Như vậy với những cải tiến đã thực hiện, phiên bản mới của mô đun quản lý không lưu có thể đáp ứng được các nhu câu cơ bản của phục vụ đào tạo quản lý không lưu tại sân. Mô đun đảm bảo được các yêu câu về mặt tiêu chí cũng như quy mô huấn luyện. Hình 8 thể hiện giao diện khởi động của mô đun mô phỏng kiểm soát không lưu.

\section{XÂY DỰNG PHẦN MỀM MÔ PHỎNG BAY}

Phần mềm mô phỏng bay giúp cho phi công có thể quan sát được khu vực xung quanh sân bay và bên trong buồng lái thông qua các chế độ điều chỉnh từ bên trong buông lái. Phần mềm mô phỏng bay có ba vai trò: đào tạo phi hành đoàn, mô phỏng hiệu suất tàu bay, môi trường và mô phỏng người hướng dẫn. Phần mềm mô phỏng bay đã giảm đáng kể thời gian, chi phí và rủi ro liên quan đến sự phát triển của hệ thống phương tiện bay. Sơ đồ chức năng của một phần mềm mô phỏng bay được mô tả trong Hình 9.

Nhằm tận dụng sự kết nối sẵn có giữa mô đun kiểm soát không lưu và phần mềm mô phỏng bay FlightGear, nhóm tác giả sẽ tiếp tục khai thác và phát triển phần mềm này, bổ sung thêm các tính năng hoặc cơ sở dữ liệu cần thiết.

Được thành lập vào năm 1997, FlightGear được phát triển bởi một nhóm tình nguyện viên trên toàn thế giới, được kết hợp bởi một tham vọng chung để tạo ra trình mô phỏng chuyến bay thực tế nhất có thể sử dụng, sửa đổi và phân phối miễn phí. FlightGear được sử dụng trên toàn thế giới bởi những người đam mê mô phỏng chuyến bay trên máy tính để bàn, để nghiên cứu trong các trường đại học và cho các triển lãm tương tác trong bảo tàng. Về mặt lập trình, FlightGear được phát triển dựa trên nhiều nền tảng ngôn ngũ lập trình khác nhau. Hình ảnh tổng hợp về cấu trúc các ngôn ngữ lập trình được sử dụng trong FlightGear được minh họa trên Hình 10.

Ngoài các ngôn ngữ lập trình kể trên, FlightGear còn sử dụng tập thư viện riêng Nasal ${ }^{11}$ để xử lý các thuộc tính bên trong phân mềm. Trong FlightGear, Nasal hỗ trợ đọc và ghi các thuộc tính bên trong, truy cập dũ liệu nội bộ thông qua các chức năng mở rộng, tạo các hộp thoại giao diện người dùng và nhiều hơn thế nữa. Đây được coi là một trong những giá trị cốt lõi và được sử dụng trong hâu hết các tác vụ của FlightGear. Trong khuôn khổ của hệ thống mô phỏng ATC, nhóm nghiên cứu tập trung chủ yếu khai thác tính năng mô phỏng khung cảnh 3D của phần mềm FlightGear. Tính năng này sẽ được sử dụng để mô phỏng khung cảnh $360^{\circ}$ tại sân bay Tân Sơn Nhất cũng như mô phỏng mô hình $3 \mathrm{D}$ của các tàu bay cũng như các trang thiết bị có trong sân bay.

Việc cập nhật dũ liệu sẽ được bắt đầu với sơ đô $2 \mathrm{D}$ của sân bay Tân Sơn Nhất. Trong bước này, nhóm nghiên cứu sử dụng dũ liệu của sân bay Tân Sơn Nhất được xuất bản tháng 2 năm 2019, như được minh họa trong Hình 11. Tại thời điểm này, các bến đỗ từ 71 đến 88 bắt đầu được đưa vào khai thác.

Dựa trên bản đồ thực tế này, nhóm nghiên cứu sẽ dựng các bản đồ $2 \mathrm{D}$ và bản đồ $3 \mathrm{D}$ dùng cho cả mô đun mô phỏng không lưu và mô đun mô phỏng bay. Việc dựng các bản đồ $2 \mathrm{D}$ và bản đồ khung cảnh $3 \mathrm{D}$ sẽ được thực hiện trên các phân mềm WorldEditor (WED) ${ }^{13}, \mathrm{AC}^{1} \mathrm{D}^{14}$. 


\section{Bảng 1: Các tác vụ chính trong các phiên làm việc}

\begin{tabular}{ll}
\hline Phiên giáo viên & $\begin{array}{l}\text { Giáo viên khởi tạo phiên làm việc và lựa chọn chế độ làm việc } \\
\text { Giáo viên tạo từng tình huống giả định và ra đưa ra chỉ lệnh trực tiếp cho tàu bay } \\
\text { Duy nhất một sinh viên kết nối vào phiên } \\
\text { Giáo viên làm mẫu và sinh viên theo dõi } \\
\text { Giáo viên thay đổi các điều kiện ngoại cảnh } \\
\text { kết nối vào phiên làm việc của giáo viên qua mạng nội bộ } \\
\text { theo dõi quá trình điểu khiển không lưu của giáo viên } \\
\text { không thể đưa ra chỉ lệnh cho tàu bay }\end{array}$ \\
\hline
\end{tabular}

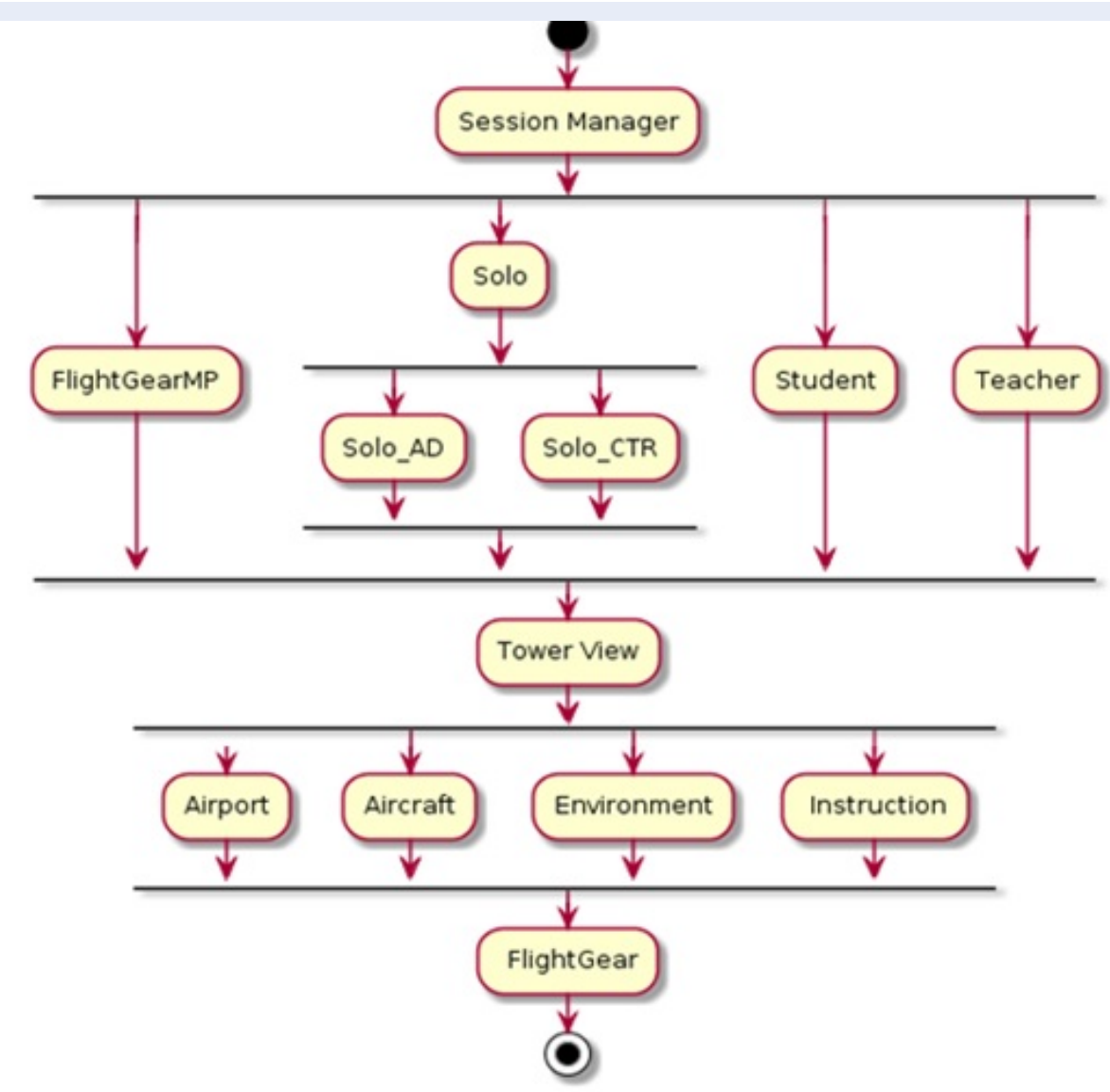

Hình 4: Sơ đồ cấu trúc các phiên làm việc trên ATC-pie

Hình 12 thể hiện bản đồ sân bay Tân Sơn Nhất được dựng lại trên phân mềm WED với đây đủ các thành phần và thuộc tính. Các vị trí đỗ mới được cập nhật cùng với quy định về chủng loại tàu bay được phép đỗ tại từng vị trí $(\mathrm{A}, \mathrm{B}, \mathrm{C}, \mathrm{D}, \mathrm{E}$ và $\mathrm{F})$. Các đường lăn của sân bay cùng với hướng di chuyển được phép cũng được thể hiện đây đủ trên bản đồ này.

Sau khi có được bản đồ $2 \mathrm{D}$, nhóm nghiên cứu sẽ tiếp tục dựng các mô hình $3 \mathrm{D}$ của các công trình xây dựng có trong sân bay như đài chỉ huy, ga hành khách, ống dẫn hành khách, các xưởng bảo dưỡng, kho hàng hóa. Quá trình dựng được thực hiện trên phần mềm AC3D. Một số công trình được minh họa trong Hình 13.

Một phân không thể thiếu được trong khung cảnh $3 \mathrm{D}$ chính là các tàu bay. Mô hình các tàu bay cũng được dựng trên phân mềm $\mathrm{AC} 3 \mathrm{D}$ dựa vào dũ liệu từ các hãng sản xuất tàu bay Cessna ${ }^{15}$, Airbus ${ }^{16,17}$, Boeing $^{18-20}$.

Tên các hãng hàng không và màu sơn của từng hãng cũng được đưa vào cơ sở dữ liệu để tăng hiệu quả thể hiện các mô hình tàu bay như minh họa trong 


\begin{tabular}{|c|c|c|c|c|c|c|c|c|}
\hline TIME & TYPE & Callsign & $\begin{array}{l}\text { Type of } \\
\text { aircraft }\end{array}$ & $\begin{array}{l}\text { Stand/ } \\
\text { Rules }\end{array}$ & From/ To & STATUS & Position & $\begin{array}{l}\text { Alt. } \\
\text { (ft) }\end{array}$ \\
\hline $14: 51$ & ARV & VFC302 & B772/M & VFR & VDPP & AIRBORNE & $10 \mathrm{NW}$ & 3000 \\
\hline $14: 52$ & DPT & FCATC & $\mathrm{B} 772 / \mathrm{L}$ & $3 / \mathrm{VFR}$ & VVCR & READY & & \\
\hline $14: 54$ & DPT & FCAT2 & B772/L & $5 / \mathrm{VFR}$ & VVCR & READY & & \\
\hline 14:55 & DPT & HVN108 & AT72/M & $5 / \mathrm{IFR}$ & VVPQ & TAXIING & & \\
\hline $14: 56$ & ARV & HVN181 & B701/M & VFR & VVDL & AIRBORNE & $10 \mathrm{NE}$ & 3000 \\
\hline $14: 57$ & DPT & VHAGL & B701/M & $3 / \mathrm{VFR}$ & VVPK & TAXIING & & \\
\hline $14: 58$ & ARV & QS-251 & AN26/M & VFR & VVCS & AIRBORN & $10 \mathrm{~S}$ & 3000 \\
\hline $14: 59$ & DPT & THA681 & A332/H & 6/IFR & VTBS & TAXIING & & \\
\hline $14: 30$ & ARV & VFC401 & B201/M & VFR & VVPQ & AIRBORNE & $10 \mathrm{SW}$ & 3000 \\
\hline $14: 31$ & DPT & ANA932 & $\mathrm{B} 772 / \mathrm{H}$ & $7 / \mathrm{IFR}$ & RJAA & READY & & \\
\hline
\end{tabular}

Hình 14. Việc xây dựng cơ sở dữ liệu này được thực hiện riêng lẻ cho từng hãng và từng loại tàu bay có kích cỡ khác nhau.

\section{THIẾT KẾ PHẦN CỨNG VÀ KẾT NỐI HỆ THỐNG}

Như đã trình bày trong các phần trước, việc bố trí các trang thiết bị phần cứng nhằm kết hợp 02 mô phỏng là mô phỏng kiểm soát không lưu (tại vị trí $\mathrm{ATC}$ ) và mô phỏng bay (tại vị trí của phi công) để phục vụ cho công việc chính là đào tạo kiểm soát viên không lưu. Việc kết nối các thiết bị sẽ được xây dựng dựa trên sơ đồ trên Hình 2 thông qua mạng LAN. Với khả năng tích hợp và mở rộng cao, phần mềm FlightGear cho phép kết hợp nhiều máy tính vào một máy chủ để xử lý hệ thống máy tính đồ họa và máy chiếu. Như vậy góc nhìn toàn cảnh $360^{\circ}$ là hoàn toàn có thể thực hiện được. Tuy nhiên trong khuôn khổ nghiên cứu, nhóm tác giả bị giới hạn về mặt trang thiết bị phân cứng. Do đó, nhóm nghiên cứu cần thực hiện thêm những chỉnh sửa để tận dụng tối đa nguồn lực phần mềm và giới hạn phần cứng. Cấu hình tối ưu được nhóm tác giả lựa chọn được minh họa trên Hình 15.

Vị trí Observator: máy chủ có cấu hình cao, card đồ họa mạnh để có thể trích xuất các khung hình, cảnh quan phức tạp (sân bay, đường băng, đường lăn, sân đỗ, các thông tin số liệu hiển thị trên sân bay như số vị trí bến đỗ, tên đường băng vv...) với độ sắc nét và tái hiện chi tiết cao mà không bị rung lắc hoặc có độ trễ, ngoài ra card đồ họa cân có tối thiếu 05 ngõ ra để truyền dẫn tín hiệu đến các thiết bị khác. Trên máy chủ đồ họa sẽ được cài đặt đông thời phần mềm FlightGear và ATC-VAA. Giáo viên sẽ khởi động phiên thực hành giáo viên, quản lý phiên thực hành và có thể can thiệp thêm bớt các tình huống thực hành cũng như thay đổi các hiệu ứng về thời gian và thời tiết đông thời thực hiện kết nối giữa mô đun mô phỏng không lưu và Flightgear thông qua chức năng "Tower view".

Hình ảnh đồ họa 3D được xuất ra trên ba khung hình tương ứng với ba màn chiếu phẳng xếp gấp khúc sẽ tái tạo khung cảnh sân bay với góc bao quát $150^{\circ}$. Việc trích xuất hình ảnh trên ba khung hình được thực hiện thông qua chỉnh sửa tệp tin camera-view.xml trong thư mục dũ liệu của FlightGear ${ }^{21}$. Nội dung của tệp tin này được minh họa trong Hình 16 . Chi tiết về cách thiết lập tên tệp tin này được trình bày trong tài liệu hướng dẫn sử dụng của nhóm nghiên cứu $^{22}$. Hình ảnh trên ba màn hình tại các điểm giao sẽ bị trùng lặp hoặc bị lệch khung hình. Để khắc phục nhược điểm này, nhóm nghiên cứu sử dụng công nghệ "warp \& blend " - được phát triển bởi NVIDIA tích hợp sẵn trên card đồ họa Geforce quadro P4000. Và đây cũng là lý do nhóm tác giả lựa chọn card đồ họa này để lắp đặt trên máy chủ đồ họa.

Vị trí ATC, Pilot: các máy tính có cấu hình cao được nối mạng với máy chủ Observator và các thiết bị khác. Tại các vị trí này, học viên sẽ khởi động các phiên thực hành sinh viên và kết nối vào phiên làm việc giáo viên chạy trên máy chủ.

Các thiết bị khác: bao gồm các thiết bị hỗ trợ khác như hệ thống dây điện, dây viễn thông, các thiết bị bộ đàm, điện thoại, đèn chiếu sáng vv... cũng cân được trang bị đây đủ để hỗ trợ cho quá trình mô phỏng diễn ra suôn sẻ và hiệu quả nhất.

Hình 17 minh hoạ hệ thống mô phỏng kiểm soát không lưu tại sân trong quá trình thử nghiệm. Trong hình là hệ thống máy chủ tại vị trí obserator và máy 


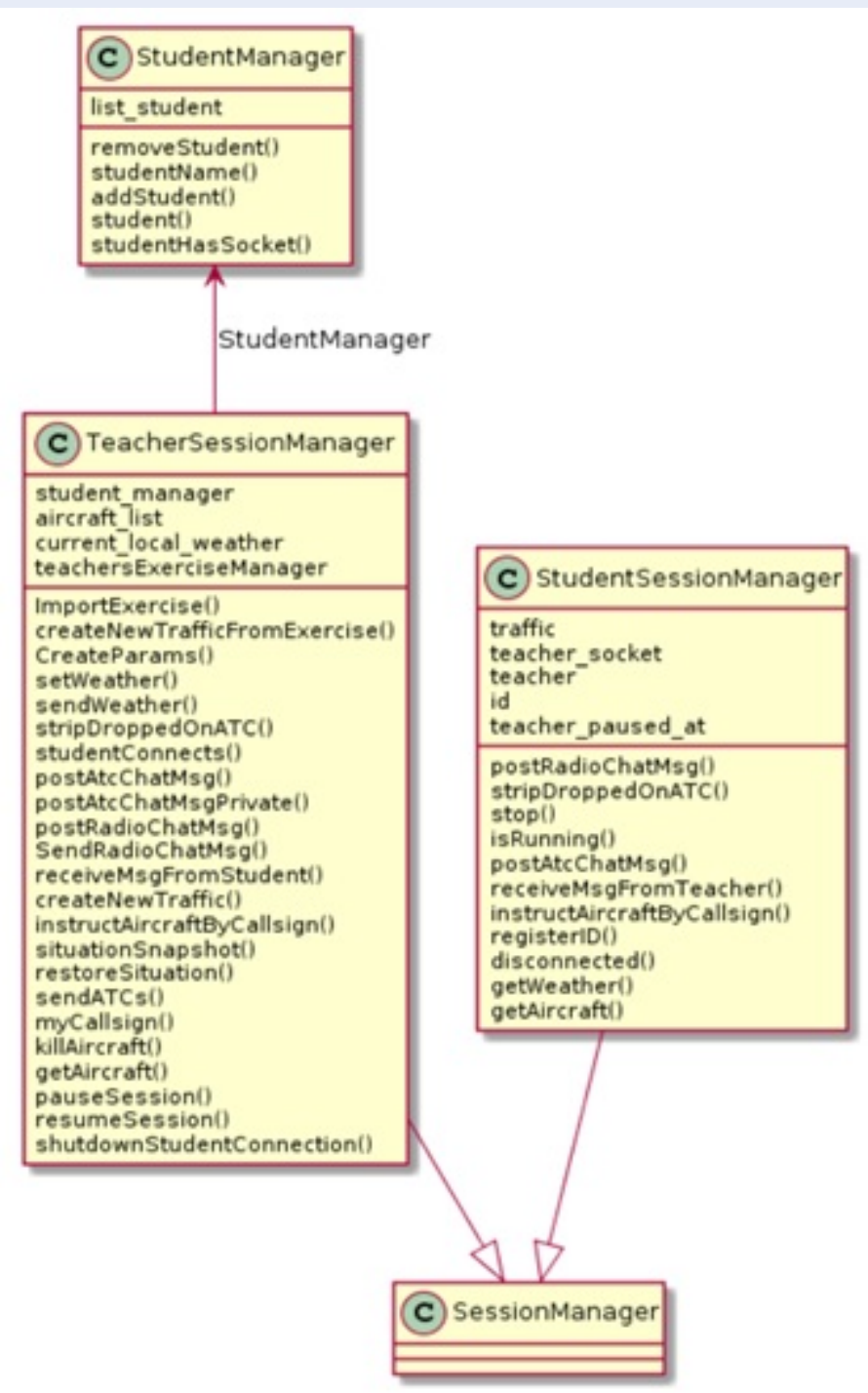

Hình 5: Thuộc tính và tác vụ của phiên làm việc giáo viên - học viên

tính tại vị trí ATC cùng với hệ thống ba máy chiếu và 3 màn chiếu.

\section{KẾT QUẢ VÀ THẢO LUẬN}

Bài báo đã xây dựng được hệ thống mô phỏng phục vụ cho công tác đào tạo kiểm soát viên không lưu bao gồm mô đun điều khiển không lưu và mô đun mô phỏng bay. Hệ thống đã tái hiện lại đường băng, đường lăn, sân đỗ, nhà ga và khu vực lân cận sân bay Tân Sơn Nhất. Mô đun mô phỏng bay được kết hợp với mô đun mô phỏng điều khiển không lưu thông qua chế độ xem Tower view, cho phép người học quan sát buồng lái tàu bay, quan sát khu vực sân bay ở nhiêu góc khác nhau.
Nhóm nghiên cứu đã thiết kế và lắp đặt một phòng thực hành kết hợp hai phần mềm trên để sử dụng trong đào tạo: gồm 2 vị trí kiểm soát viên không lưu, 2 vị trí phi công giả định và 1 vị trí giám sát. Đông thời để phục vụ cho công tác liên lạc giữa kiểm soát viên và phi công, nhóm nghiên cứu cũng đã tiến hành nghiên cứu hệ thống liên lạc qua đàm thoại để kết nối hai vị trí. Nhóm đã tiến hành chạy mô phỏng, thử nghiệm kiểm tra các tính năng, hệ điều hành, đồ họa, tính ổn định của phần mềm.

Mục tiêu phục vụ đào tạo cũng được bổ sung hoàn chỉnh với hệ thống bài tập thực hành được soạn sã̃n. Các bài kiểm tra chạy mô phỏng trên phần mềm để đánh giá khả năng vận hành của hệ thống trang thiết bị cũng như kiểm nghiệm các tính năng và kết quả 


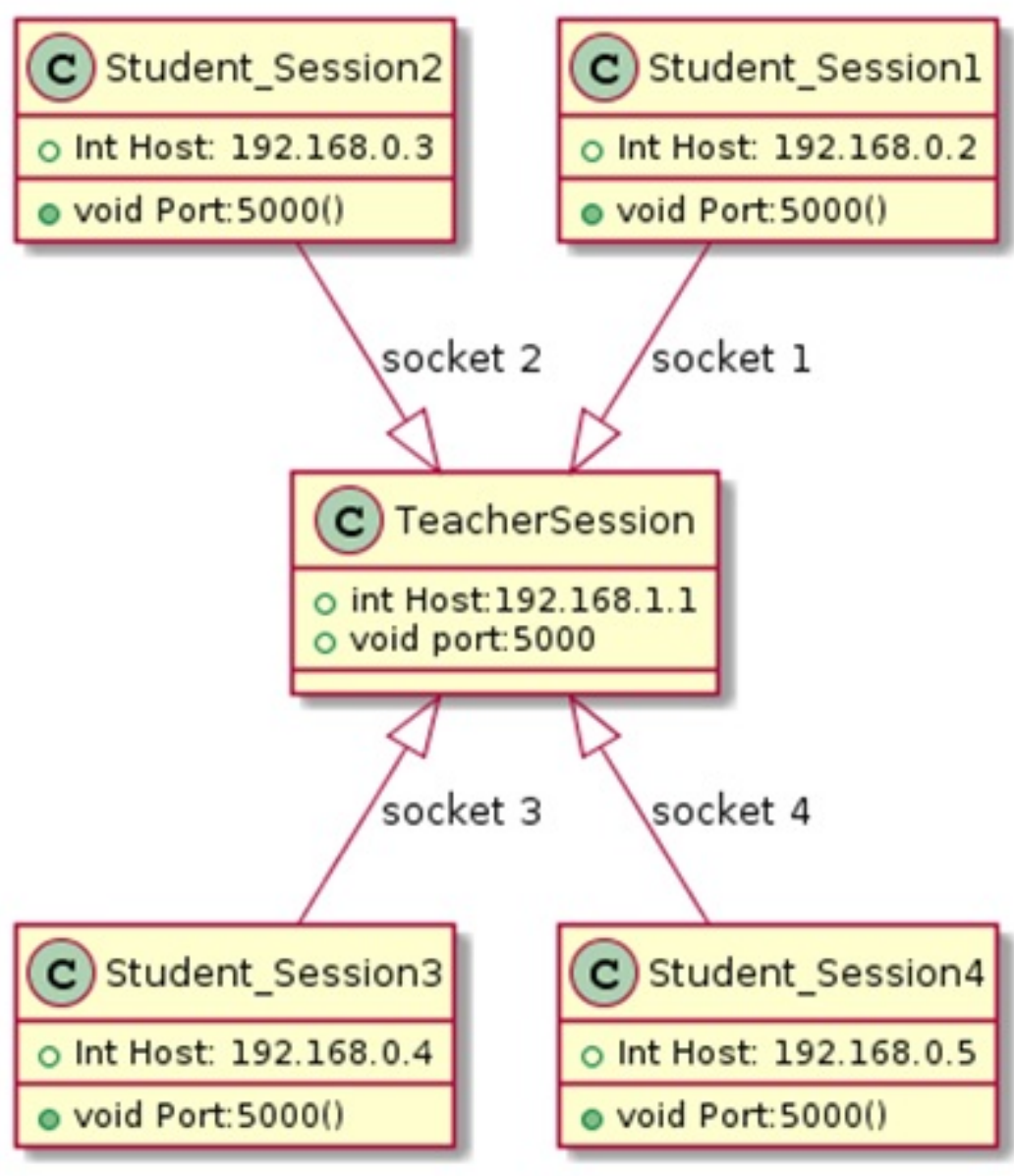

Hình 6: Sơ đồ kết nối phiên giáo viên - học viên mở rộng

mang lại. Những kết quả bước đầu của hệ thống đáp ứng tốt nhu câu của người sử dụng mà đối tượng chủ yếu ở đây chính là các học viên với vai trò là kiểm soát viên không lưu và các giáo viên huấn luyện kiểm soát không lưu.

Tại các công ty quản lý bay, các ca mô phỏng được thực hiện nhiêu giờ liên tục. Việc này đặt ra yêu câu về tính ổn định của hệ thống mô phỏng và các hệ thống phụ trợ khác như thông gió, làm mát. Để giải quyết các vướng mắc này, nhóm nghiên cứu cần tiến hành thêm một số nghiên cứu khác nhằm cân bằng và tối ưu các nhu cầu cũng như chi phí của hệ thống. Các giải pháp sẽ được đề cập đến trong các nghiên cứu, thảo luận tiếp theo của đề tài.

\section{KẾT LUẬN}

Hệ thống mô phỏng kiểm soát không lưu tại sân được xây dựng chi tiết với bối cảnh tại sân bay quốc tế Tân Sơn Nhất đã đáp ứng được nhu câu giảng dạy, học tập và thực hành của giảng viên, sinh viên khoa Không lưu, Học viện Hàng không Việt Nam. Hệ thống đã chứng minh được hiệu quả kinh tế cũng như giá trị học thuật so với các hệ thống nhập ngoại đắt tiền đang được triển khai tại các trung tầm quản lý bay. Mô hình này có thể tiếp tục được bổ sung, nâng cấp đê đáp ứng nhu câu đào tạo kiểm soát viên không lưu cho các sân bay trong nước và quốc tế khác.

\section{XUNG ĐộT LợI ÍCH}

Nhóm tác giả cam đoan rằng không có bất kỳ xung đột lợi ích nào trong công bố bài báo.

\section{ĐÓNG GÓP CỦA CÁC TÁC GIẢ}

Lưu Văn Thuân tham gia vào việc đưa ra ý tưởng nghiên cứu, mô hình tổng thể và mô đun tháp điều khiển không lưu. Hồ Thị Vũ Hiền tham gia việc thu thập dữ liệu sân bay Tân Sơn Nhất và xây dựng các bản đô sân bay và hệ thống phụ trợ. Phạm Minh Vương đã đóng góp xây dựng mô đun mô phỏng bay, thiết kế phân cứng và kết nối các hệ thống. 


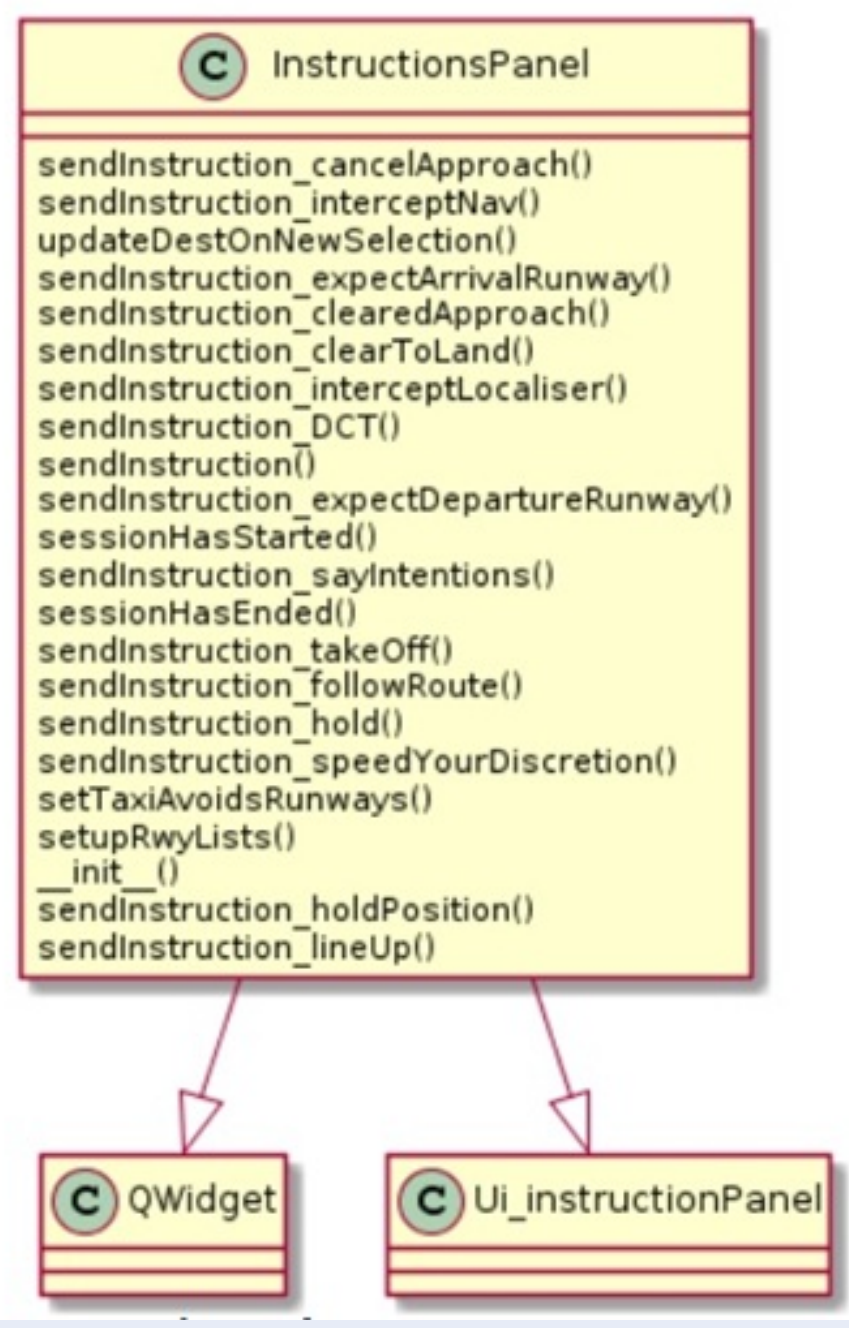

Hình 7: Các tác vụ điều khiển tàu bay trong phiên thực hành sinh viên

\section{LờI CẢM ƠN}

Nghiên cứu này được tài trợ bởi Bộ Giao thông Vận tải trong khuôn khổ đề tài mã số DT183040. Chúng tôi xin cảm ơn Học viện Hàng không Việt Nam, Bộ Giao thông vận tải đã hỗ trợ thời gian, phương tiện và cơ sở vật chất cho nghiên cứu này.

\section{TÀI LIÊUU THAM KHẢO}

1. Lưu T. Nghiên cứu, phục hồi hệ thống giả định phòng thức tập kiểm soát không lưu phục vụ đào tạo huấn luyện. Học viện Hàng không. 2010;

2. Dabare P, et al. Foss Based Air Traffic Control Simulator," Int. J. Res. -GRANTHAALAYAH. 2016;4(12):170-177. Available from: https://doi.org/10.29121/granthaalayah.v4.i12.2016.2406.

3. Sidhom M. A teamwork-oriented air traffic control simulator. Calhoun. 2006;

4. OpenScope Air Traffic Control Simulator. openScope. [Online] [Accessed: 15-Aug-2019];Available from: http://openscope.co.

5. OpenRadar. SourceForge. [Online]. [Accessed: 15-Aug2019];Available from: https://sourceforge.net/projects/ openradar/.

6. ATC-pie. SourceForge. [Online][Accessed: 15-Aug2019];Available from: https://sourceforge.net/projects/atc-pie/.

7. FlightGear Flight Simulator. [Online]. [Accessed: 15-Aug2019];Available from: https://www.flightgear.org/.

8. Rossum G, Drake FL. Extending and Embedding the Python Interpreter. 2001;p. 54.

9. Qt | Cross-platform software development for embedded \& desktop. [Online] [Accessed: 15-Aug-2019];Available from: https://www.qt.io/.

10. Zheng S, Huang Q, Jin J, Han J. Flight Simulator Architecture Development and Implementation. 2009 International Conference on Measuring Technology and Mechatronics Automation, Zhangjiajie, Hunan, China. 2009;p. 230-233. Available from: https://doi.org/10.1109/ICMTMA.2009.185.

11. Nasal introduction - FlightGear wiki. [Online]. [Accessed: 15Aug-2019].;Available from: http://wiki.flightgear.org/Nasal_ introduction.

12. Tập bổ sung AIP Việt Nam - AIP SUP. Cục Hàng Không Việt Nam. 2019;A02/19.

13. WorldEditor Manual. [Online]. [Accessed: 15-Aug2019];Available from: https://developer.x-plane.com/manuals/ wed/. 


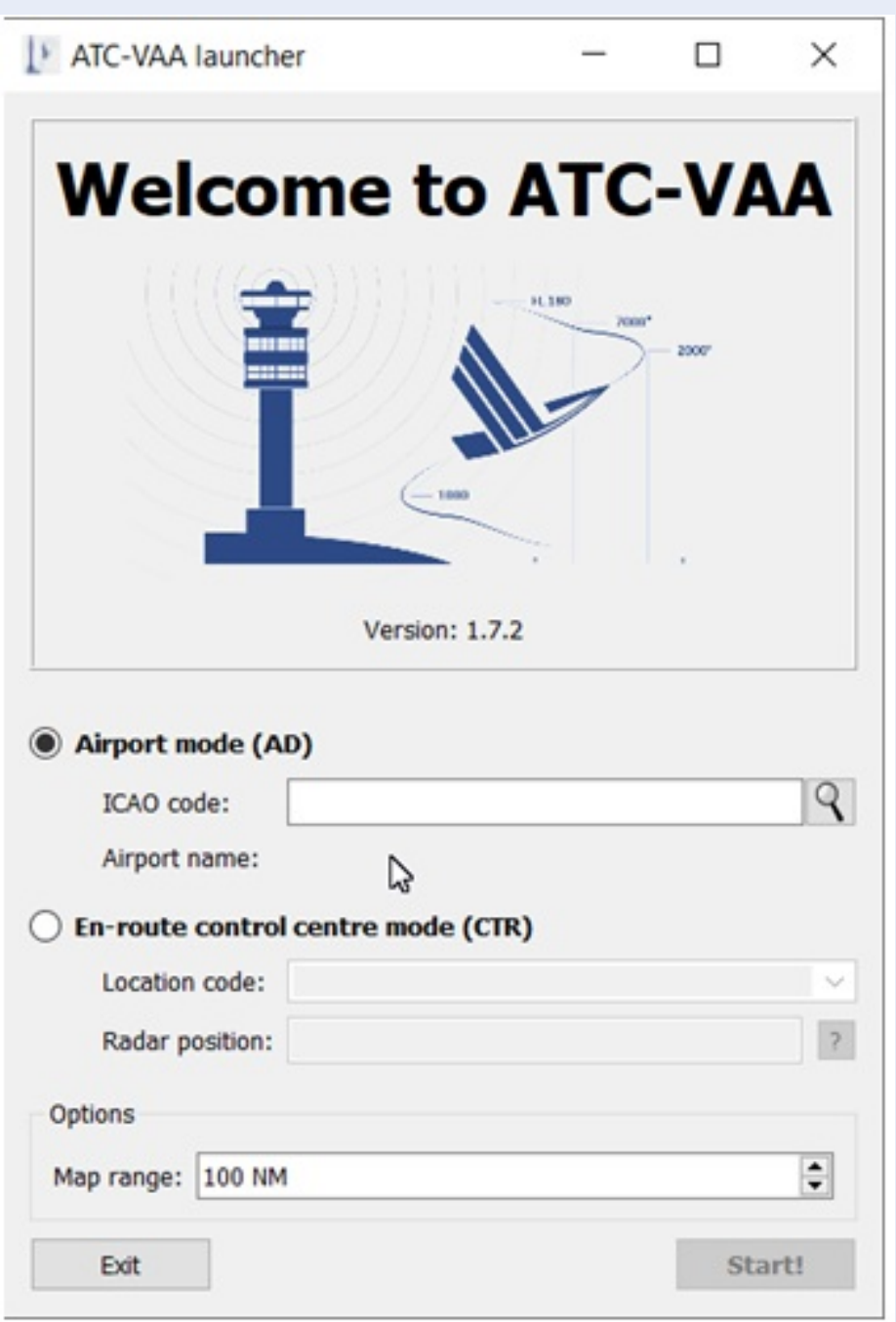

Hình 8: Giao diện khởi động của mô đun kiểm soát không lưu

14. AC3D. [Online]. [Accessed: 15-Aug-2019];Available from: https://www.inivis.com/.

15. Cessna. Model 172S - Specification and Description. 2012;

16. Airbus. A320, Aircraft Characteristics airport and maintenance planning. 2005;

17. Airbus. A340-200/300, Aircraft Characteristics airport and maintenance planning. 2005;

18. Boeing. D6-58322 707 Airplane Characteristics for Airport Planning. 1968;.
19. Boeing. D6-58325-6 737 Airplane Characteristics for Airport Planning. 2005;.

20. Boeing. D6-58327 757-200/300 Airplane Characteristics for Airport Planning. 2002;

21. Configure camera view windows - FlightGear wiki. [Online]. [Accessed: 16-Aug-2019];Available from: http://wiki. flightgear.org/Howto:Configure_camera_view_windows.

22. Lưu VT, Hồ TVH, Phạm MV. Hướng dẫn sử dụng hệ thống mô phỏng kiểm soát không lưu tại sân: 


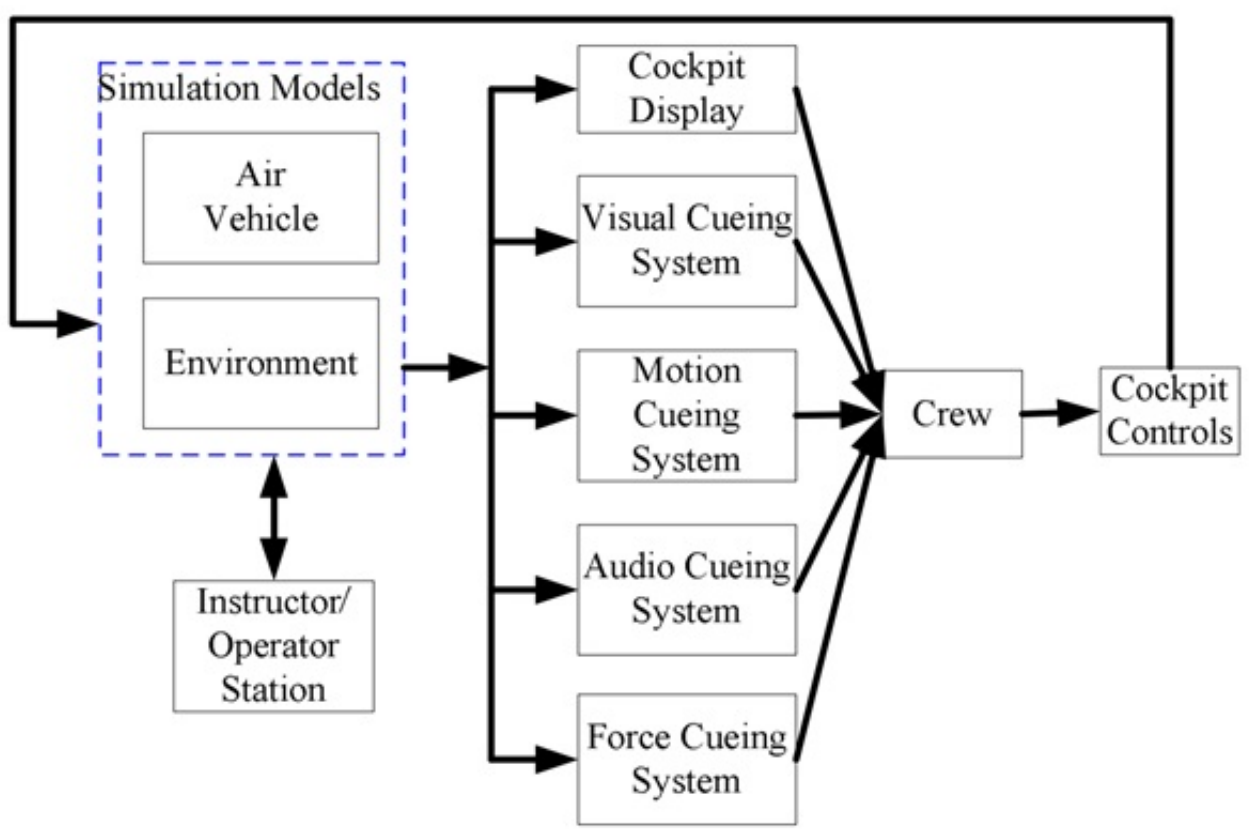

Hình 9: Sơ đồ chức năng phần mềm mô phỏng bay ${ }^{10}$

\section{FlightGear Canvas}

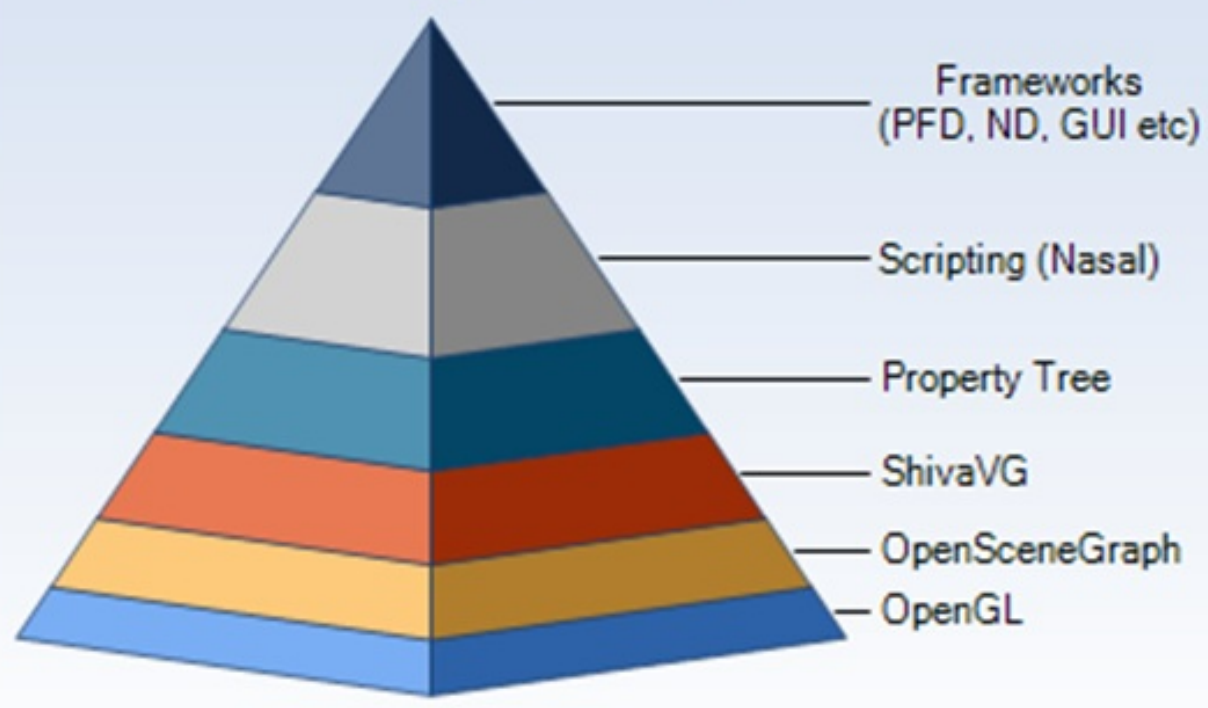

Hình 10: Cấu trúc các ngôn ngữ lập trình trên FlightGear 


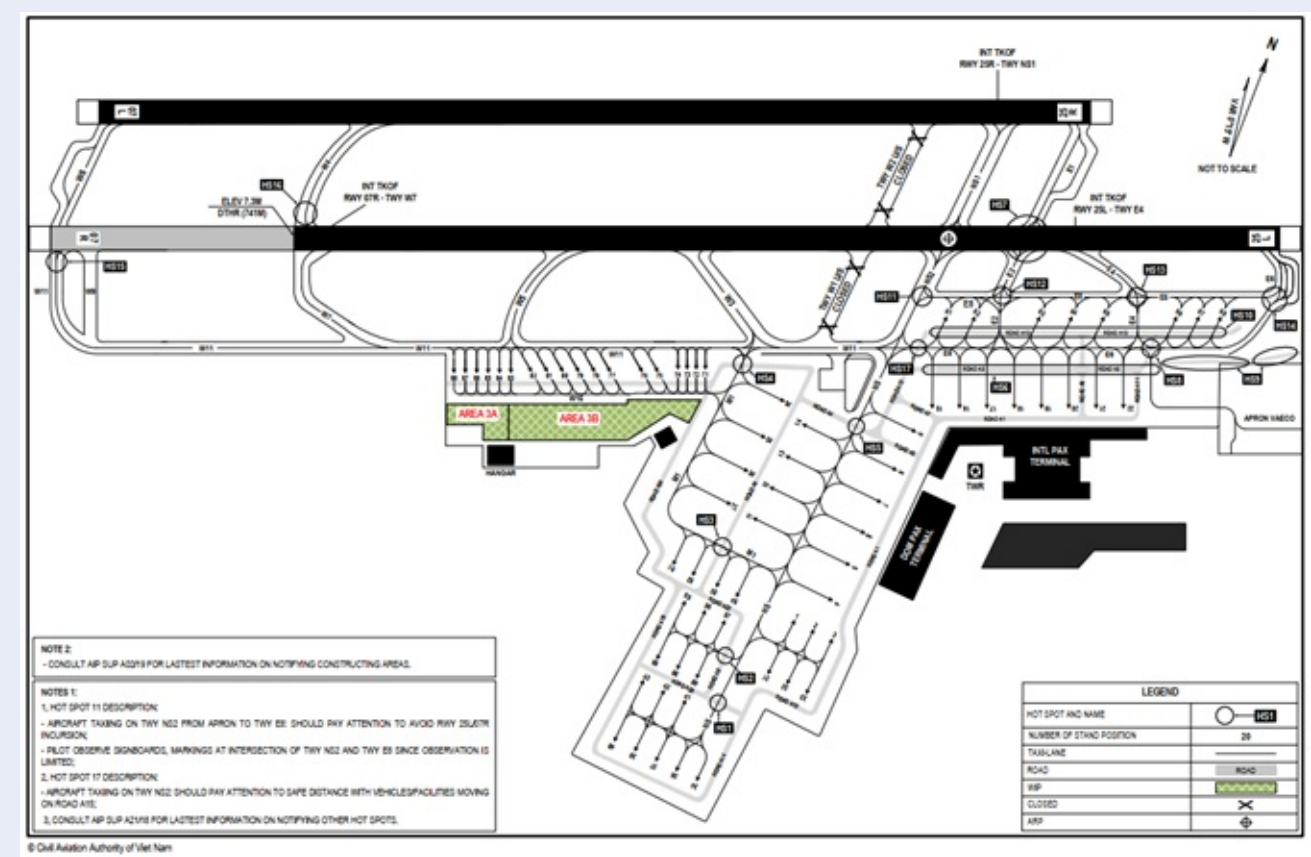

Hình 11: Bản đồ sân bay Tân Sơn Nhất ${ }^{12}$

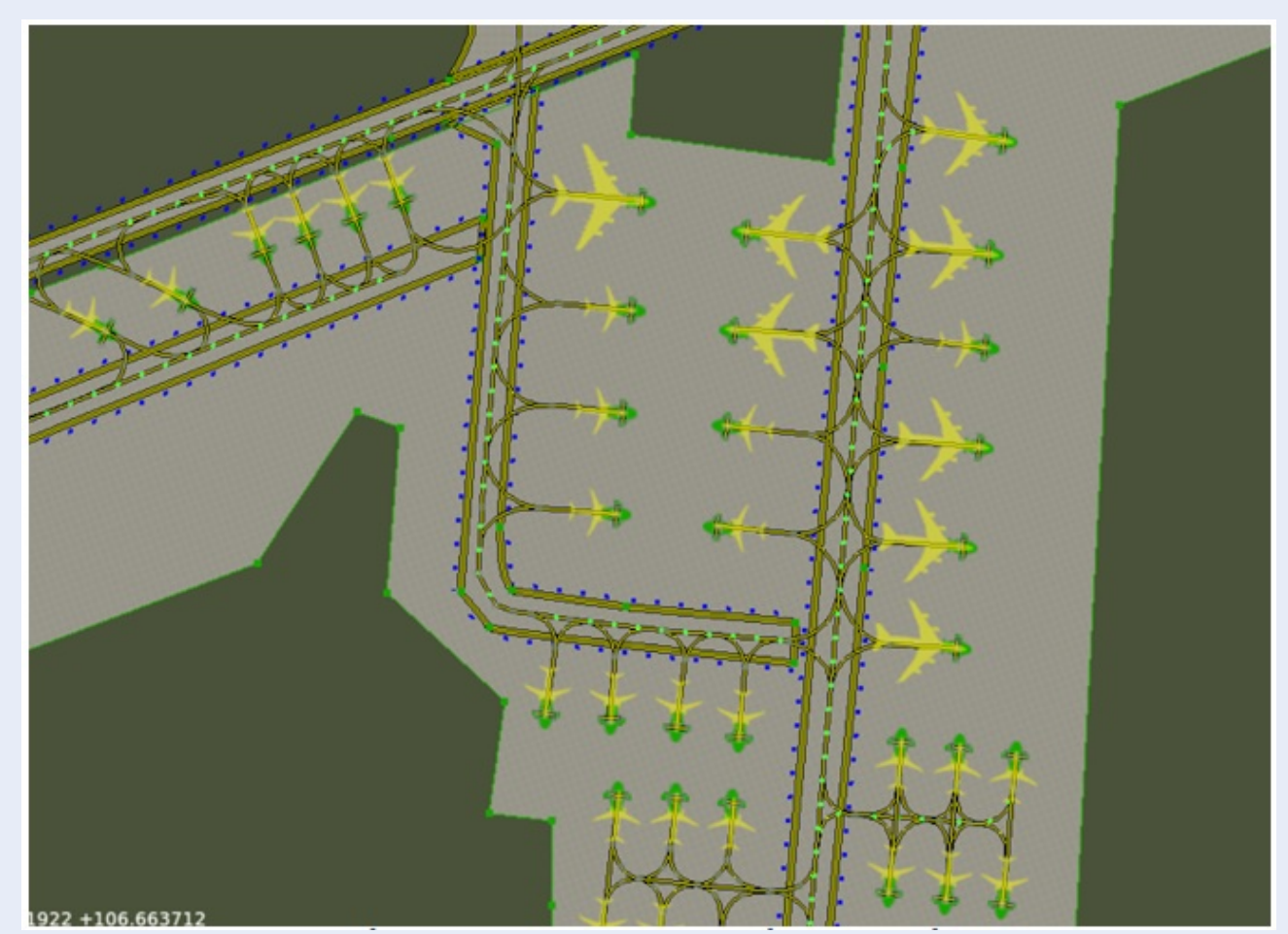

Hình 12: Bản đồ sân bay Tân Sơn Nhất được số hóa trên WED 


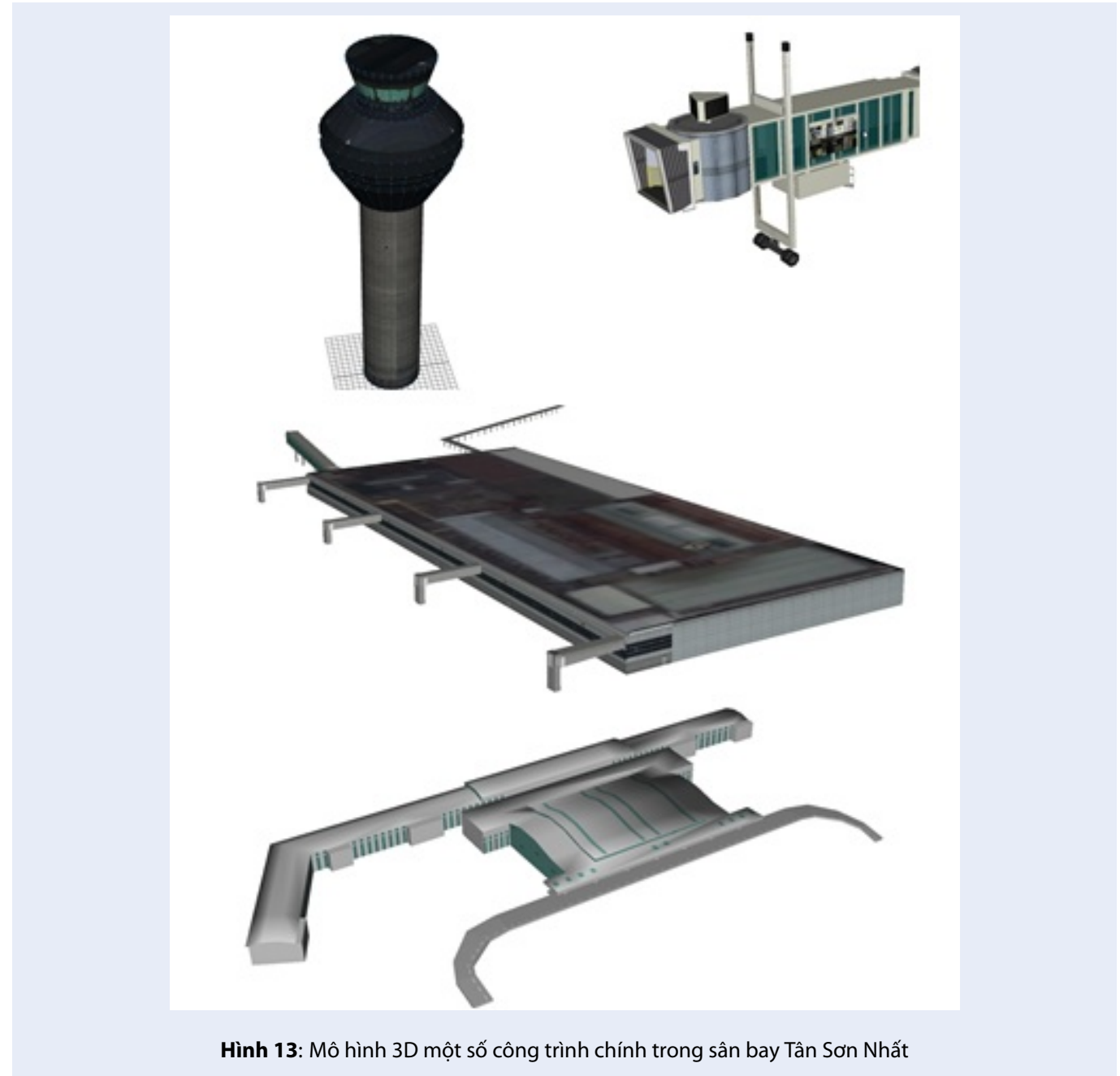



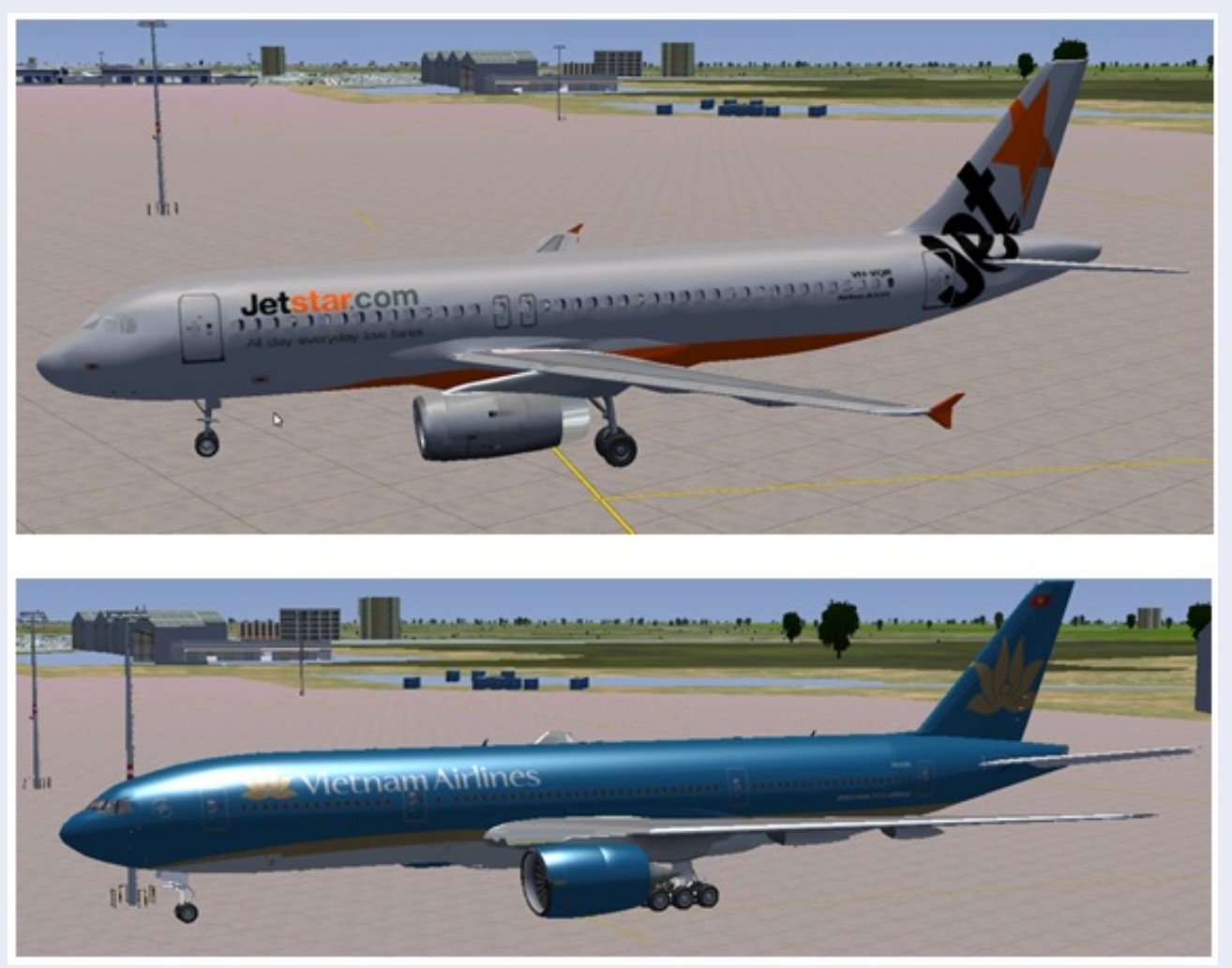

Hình 14: Mô hình 3D một số máy bay được dựng 


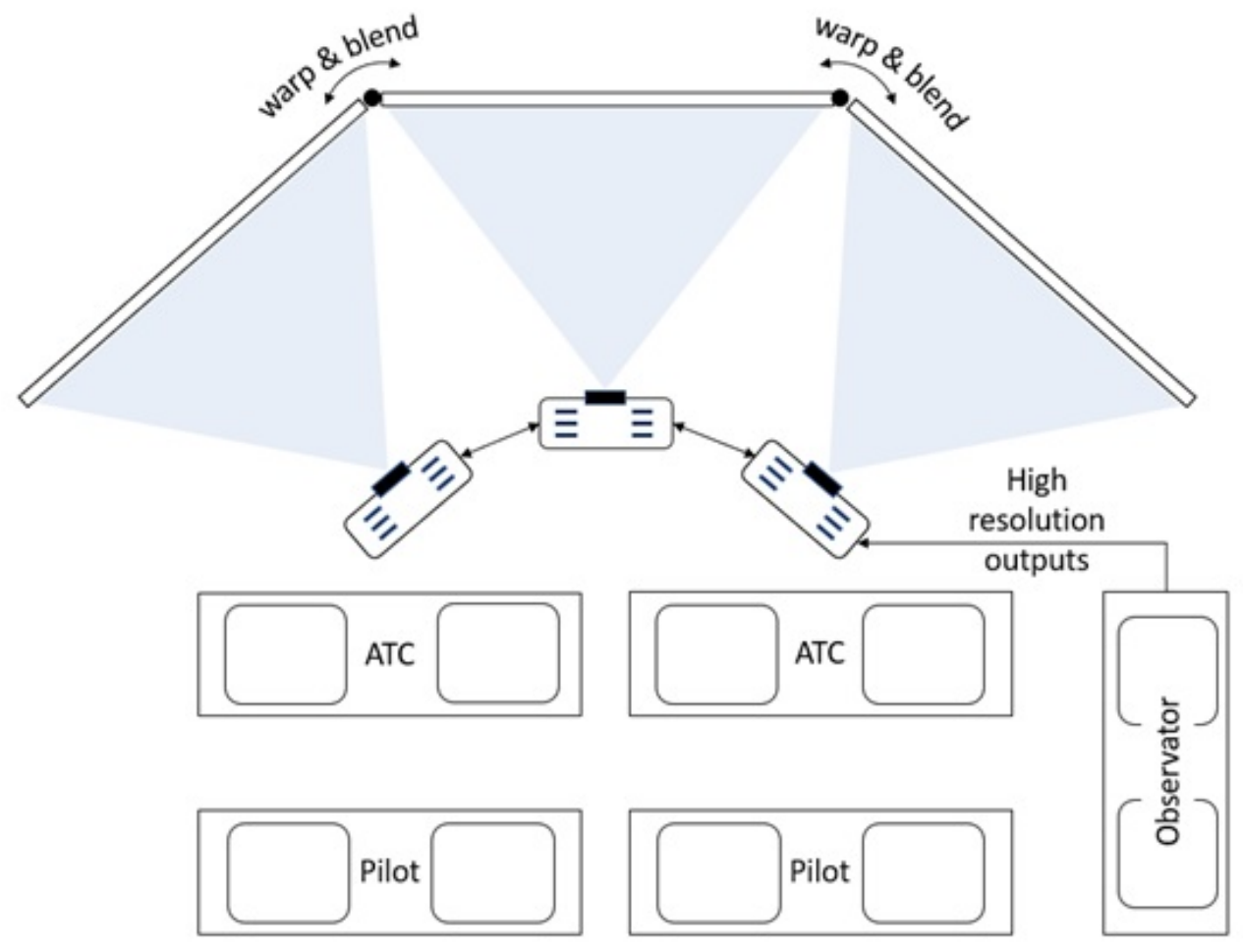

Hình 15: Sơ đồ hệ thống mô phỏng kiểm soát không lưu tại sân

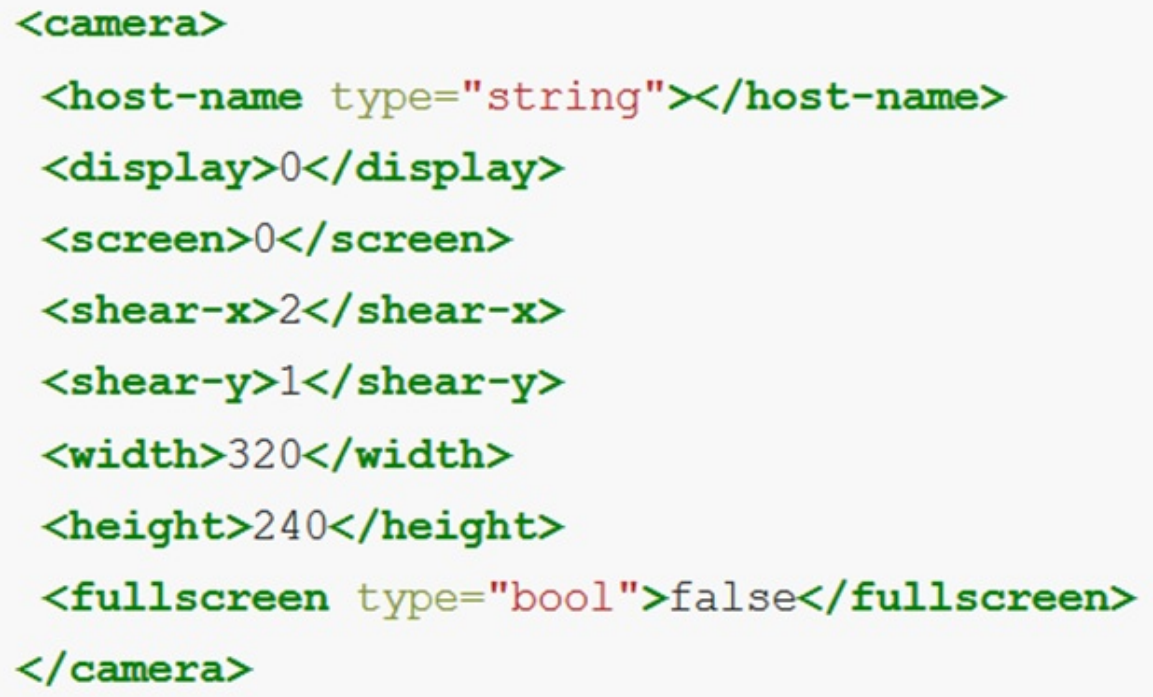




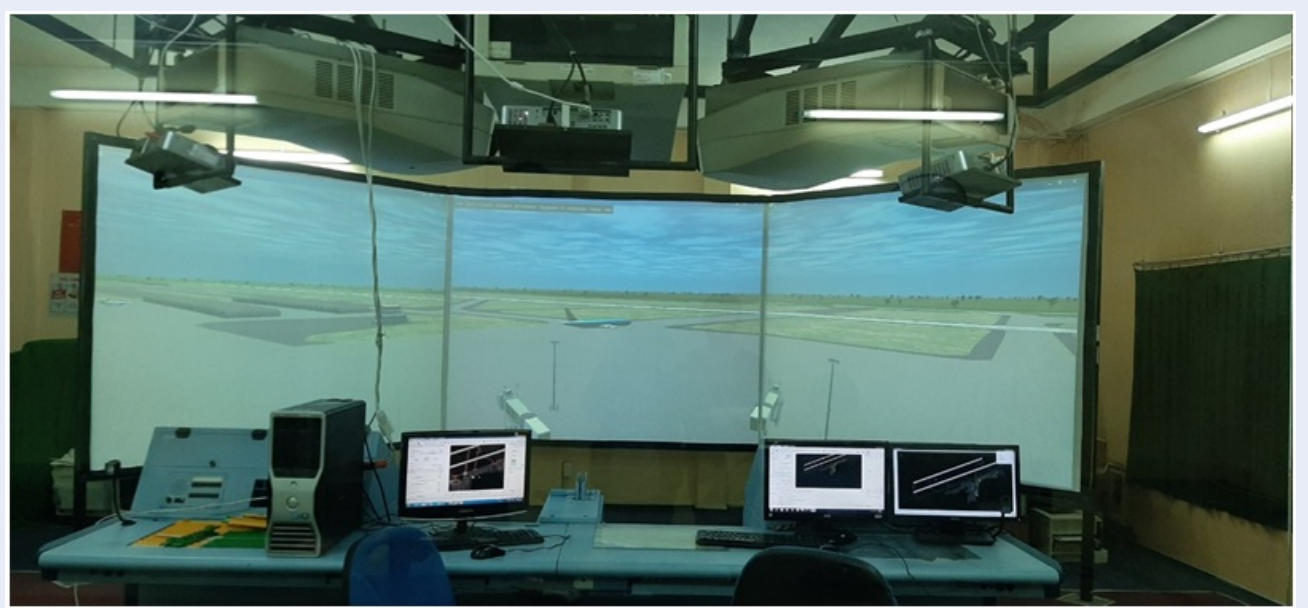

Hình 17: Thử nghiệm hệ thống mô phỏng kiểm soát không lưu tại sân 


\title{
Development of air traffic control simulator system applied in education and training
}

\author{
Van Thuan Luu ${ }^{1,}{ }^{*}$, Thi Vu Hien $\mathrm{Ho}^{2}$, Minh Vuong Pham²
}

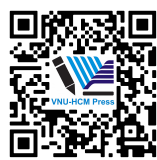

Use your smartphone to scan this QR code and download this article

\section{ABSTRACT}

This is a research and develop paper about air traffic control process at the airport in national scientific research project. Air traffic control simulation system has become familiar in developed countries. Moreover, in Vietnam, the demand for air traffic control systems is increasing due to the boom of the civil aviation industry in general and air navigation service providers in particular. However, there is any research or development on this system in Viet Nam. The Northern and Southern Flight Management Companies all import control simulation systems at a very high cost from foreign aviation research companies and groups. Many other flight management companies also have a high demand for this system, including military units. This demand prompted the research team to find a solution to build an air traffic control simulation system in accordance with domestic training needs. Based on individual open-source simulation software with some basic features, the team has successfully built an aerodrome control simulation system that recreates the visually appealing 3D visualization used in training of air traffic controllers. This system is currently being applied to train air traffic management at Vietnam Aviation Academy.

Key words: 3D graphic, air traffic control, aerodrome control, opensource, simulator
${ }^{1}$ Falcuty of Aviation Engineering, Vietnam Aviation Academy, 104 Nguyen Van Troi Street, Phu Nhuan District, Ho Chi Minh City, Vietnam.

${ }^{2}$ Falcuty of Air Traffic, Vietnam Aviation Academy, 104 Nguyen Van Troi Street, Phu Nhuan District, Ho Chi Minh City, Vietnam

\section{Correspondence}

Van Thuan Luu, Falcuty of Aviation Engineering, Vietnam Aviation Academy, 104 Nguyen Van Troi Street, Phu Nhuan District, Ho Chi Minh City, Vietnam.

Email: thuanlv@vaa.edu.vn

History

- Received: 16-08-2019

- Accepted: 25-3-2021

- Published: 30-4-2021

DOI : 10.32508/stdjet.v3iSI2.557

\section{Check for updates}

\section{Copyright}

(.) VNU-HCM Press. This is an openaccess article distributed under the terms of the Creative Commons Attribution 4.0 International license.

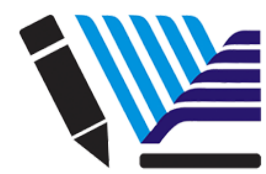

VNU-HCM Press
Cite this article : Luu V T, Ho T V H, Pham M V. Development of air traffic control simulator system applied in education and training. Sci. Tech. Dev. J. - Engineering and Technology; 3(SI2):SI158SI175. 